\title{
Achieving Sustainability and Biodiversity Conservation in Agriculture: Importance, Challenges and Prospects
}

\author{
Emogine Mamabolo ${ }^{1,2 *}$, Maria M. Makwela ${ }^{1,2}$ and Toi J. Tsilo ${ }^{2}$
}

\begin{abstract}
Concerns over the two-legged march towards sustainability and biodiversity conservation in agricultural landscapes have sparked debates globally; both in research and development, socioeconomics and policy planning. While others argue that sustainable and biodiversity conserving agriculture is impractical, an increasing body of evidence continues to recognise the importance of biodiversity for human survival and environmental stability. Because of this recognition, the UN decided to integrate and prioritise biodiversity conservation in its sustainable development goals. Although the concept of biodiversity is recognised as a potential coping strategy for climate change and crop production challenges; the practicality of its integration in agriculture remains a challenge. In this paper, some of the important prospects that can support and facilitate biodiversity conservation in agricultural landscapes are briefly discussed. While we recognise that the path to sustainability is not going to be easy, we emphasise the need for integrated research from both the sectors of agriculture and conservation to be prioritised, to reconcile productive sustainable agriculture and biodiversity conservation. Such research should target trade-offs and synergies which can make it possible for these sectors to coexist and survive in their coexistence. This will be highly beneficial to facilitate and guide the sustainability and conservation policy planning.
\end{abstract}

Keywords: sustainable intensification; resilience; biodiversity conservation; ecosystem services; food security

\section{Introduction}

The current worldwide concern is achieving agricultural sustainability. Amidst the current scenario of climate change; the challenges of population growth, food insecurities and resource scarcity are putting huge pressure on production systems ( Gliessman, 2015). Within this narrative, the agricultural sector faces a dual challenge of (1) producing enough food for an ever-increasing population, which is expected to be 9.1 billion by the year 2050 (Adenle et al., 2019; FAO, 2008), (2) without compromising the environment and natural resources; and this must be done on limited land, using limited soil and water resources that are likely to be further stressed by the changing climate (Altieri et al., 2016). The sustainable development goals of the UN (United Nations) generally strive to support the demands of the existing generation without affecting other upcoming generations and the provision capacity of their needs (Pretty, 2008). Because of the recognition of adverse effects caused by agriculture on natural resources and environmental health; calls for promoting sustainable intensification in agriculture have become increasingly important to advance food security and mitigate the negative effects caused by the changing climate and intensive agricultural models (FAO, 2009; Gomiero 
et al., 2011; Moore, 2015).

The concept of sustainability has been studied and pronounced in various levels of references and context ranging from environmental to socioeconomics. From an agricultural perspective, to fully understand the underlying principles for sustainability, one must appreciate the significance of biodiversity (Brussaard et al., 2010, 1993). Biodiversity, also known as " biological diversity" is considered a key determining factor of ecological function, sustainability and stability (Balvanera et al., 2006; Brown and Williams, 2016). The term is generally described as the occurrence of a great quantity of diverse fauna and flora which build a balanced environment (Barrios, 2007). The soil biodiversity is the key component for sustainability, also known as agricultural biodiversity; it refers to every terrestrial component in the soil. This biodiversity is highly diverse and complex, underpinning a multitude of ecosystem processes, which regulate ecosystem functionality below ground (Barrios, 2007; Tscharntke et al., 2012). Because soil biodiversity is responsive to management and environmental changes, it is regarded as the bioindicator, providing stability and resilience against disturbances and soil stresses caused by anthropogenic activities and climate change (FAO, 2008; Jing et al., 2015). Soil biodiversity is rigorously declining in agricultural landscapes, and the loss of species with key functions is predicted to have detrimental effects on agroecosystems functionality and productivity (Barrios, 2007; Brussaard et al., 2010). Although biodiversity provides important benefits in agriculture, conservation efforts continue to be highly embraced in forestry and floristic ecosystems while agricultural landscapes are neglected. This paper presents a synopsis of the importance of soil biodiversity conservation for agricultural functioning and sustainability. Using evidence from literature synthesis, we outline prospects for biodiversity conserving agriculture by answering the critical question: Can agriculture achieve sustainability while conserving biodiversity? And if so, how can this be achieved?

\section{The importance of soil biodiversity in agriculture}

Soil together with its biological components is believed to form the basis for food security and sustainability through agriculture by promoting and safeguarding important ecosystem processes (Crotty et al., 2015) such as nutrient regulation, decomposition, water retention as well as the amendment of the soil physicochemical properties (Cardinale, 2011; Barrios, 2007), all of these significantly contributes towards resilience and productivity in a system. Biodiversity in agriculture is essentially promoted as the potential coping strategy to mitigate threats associated with changing climate and sustainability uncertainties (FAO, 2009). A considerably high number of biodiversity in agricultural soils could potentially benefit smallholder farmers who do not have systems market insurance by providing "biological insurance" against possible crop failures through ecosystem services the biodiversity provides (Diaz et al., 2006). This is directly linked to the "hypothesis of ecological assurance" which suggests that biodiversity may provide ecological insurance and alleviate effects of changing climate, because different species react differently to change, resulting in the more foreseeable collective community or ecosystem goods (Petchey, 2007). Ecological benefits which soil biodiversity provides to the society are measured in ranks of environmental, economic and food security: 
(1) Environmental security: The extreme usages of chemical inputs in the environment have led to many sources of water being contaminated (Khumalo et al., 2012). Biodiversity in the soil detoxifies hazardous chemicals and absorbs excess nutrients that become pollutants as soon as they reach the groundwater surface. Thereby, providing resilience against environmental threats caused by pollution and land degradation.

(2) Economic security: Sustainable management of biodiversity below and above ground enhances the efficiency of natural resources and processes, thereby cutting input and production costs such as pesticides application, due to biological pest control and less fertilisation due to the cycling of nutrients and less leaching from the ground surface. This can potentially benefit smallholder and poorly resourced farmers who lack the revenue to access inorganic inputs ( Petchey, 2007).

(3) Food security: To secure food for an estimated 9.1 billion human population, soil degradation has to be avoided through good soil management practices (FAO, 2008). Soil biological management improves crop yield and quality through biological pest and disease management and promotes plant growth by engineering the soil to be healthy and productive.

\section{Loss of biodiversity due to agricultural intensification}

A revolutionary naturalist, Wilson (1992), widely known as the father of biodiversity greatly emphasised that " $W$ e should preserve every scrap of biodiversity as priceless while we learn to use it and come to understand what it means to humanity". Despite this important remark, science and society are still confronted with the loss of biodiversity and associated services as the result of anthropogenic activities including agriculture. Unquestionably, agriculture has had its fair share of degrading natural resources and biodiversity is not exceptional. Biodiversity loss is increasing at an accelerated rate globally and agriculture is frequently identified as the key contributing factor to this loss. As a result, the future prospects of intensive agricultural models have been questioned by various stakeholders (DEA, 2015; FAO, 2018; Millennium Ecosystem Assessment, 2005), because of the threats it poses on the environment and humans (Altieri et al., 2016). In the past, agriculture depended on natural internal resources, such as biological pest control, recycling of organic matter and precipitation patterns for acceptable yields (Altieri, 2002), however, since the introduction of agricultural intensification also known as the "green revolution" during the 1960s, the biological and natural resources have been seriously neglected. The currently adopted conventional agricultural models characterised by monoculture cultivations, synthetic pesticide usage, mineral fertilisation and tillage have been linked with the degradation of important natural resources i.e water and soil (Twardowski, 2010) as well as aggravated effects on soil biological communities and their functions in the soil ecosystem (Römbke et al., 2009). Because soil biodiversity governs ecosystem functioning, its loss in agriculture is predicted to have negative effects such as erosion, low infiltration rates, reduced organic matter decomposition and carbon sequestrations, which could all compromise soil resilience and therefore a loss in productivity and sustainability. 


\section{Can agriculture achieve sustainability while conserving biodiversity?}

Given the significance of biodiversity and the increased records of its losses in agricultural environments, policymakers have taken a step to search for reliable approaches that can promote sustainable food production while reducing biodiversity loss (Brussaard et al., 2010). Within this narrative, sceptical views have emerged regarding the possibilities of biodiversity conservation in agriculture. These views have further sparked debates in most sustainability and biodiversity conservation dialogues and the most important and thought-provoking question being asked is Can agriculture achieve sustainability while conserving biodiversity? And if so, how can this be achieved? With the basis from a growing body of literature, we would like to believe that there is indeed a possibility. This belief is based on the developments in agro-ecology research which continue to increase confidence about the likelihood of agricultural systems to achieve sustainable food production without degrading natural resources. Investigative technical reports from various stakeholders, in particular, suggest that a shift to sustainable intensification could conserve ecological resources such as biodiversity while ensuring economic, environmental and social benefits to rural communities and poorly resourced farmers and therefore, sustainability and food security (FAO, 2015, 2009; IAASTD, 2009; IPES-Food, 2016). While recognising that biodiversity-conserving agriculture can be feasible, a considerable amount of research published on topics of agriculture, ecosystems and environment ( Bender et al., 2016; Sileshi et al., 2008; Van Hook, 1994) also recognise that this cannot be accomplished instinctively. The prospects of biodiversity-conserving agriculture will depend to a greater degree on broad perspectives and methodologies, including, (1) adoption of biodiversity-based agriculture, (2) cooperation from stakeholders (3) improved environmental literacy and (4) advances in policy planning and application. In this way, appropriate skills and knowledge from various specialists in agriculture, conservation ecology and policy (Garibaldi et al., 2019) can be integrated and then translated to model biodiversity-conserving agriculture.

\subsection{Adoption of sustainable intensification models}

The concept of sustainable intensification has become the key topic of interest in the global policy arena and academic research, because of its potential to lessen the threats linked to the changing climatic patterns, natural resource degradation, food productivity and the growing human population (FAO, 2009; Khumalo et al., 2012; Sithole et al., 2016). It is generally accepted as crop production that increases yield margins without affecting natural resources and the environment (Sileshi et al., 2008). Although not widely adopted in most parts of the world; innovative and resource-saving, sustainable intensification strategies have been established globally to improve food security and reduce agricultural biodiversity decline (Garibaldi et al., 2019). These strategies involve the introduction of ecological principles in agriculture by adopting cultivation practices which conserve and utilise biodiversity to improve agricultural sustainability and quality (Khumalo et al., 2012).

The concept of agroecology, also known as "agroecological intensification" is one of the models which has developed within science and social grounds as a generally reasonable and sustainable substitute to intensive models (Palomo-Campesino et al., 2018). This 
approach uses principles of ecology to redesign and manage cultivation ecosystems to be productive, resilient and sustainable (Gliessman, 2015; IPES-Food, 2016) as well as to promote ecological functions using methods which moderate and possibly eradicate the necessity for conventional practices (Isgren and Ness, 2017). Agro-ecology is best described by Gliessman (2015) as a "food system restructuring strategy, to achieve ecological, economic, and social sustainability". This concept is supported by several stakeholders in the industry as a manner of transformation to sustainable and unbiased food production systems. Although it is documented to have positive benefits to the environment and society, agroecology continues to be marginalised (De Schutter, 2010; Holt-Giménez and Altieri, 2013), only a few countries have managed to transition to agro-ecology.

Conservation agriculture is another sustainable intensification model. Described as a technology for resource-preserving agricultural production system; conservation agriculture attempts to reach acceptable yields while preserving the environment (FAO, 2008; Sithole et al., 2016). This model which is characterised by the permanent cover of the soil, crop diversity and reduced soil disturbance has developed as a viable alternative to intensive agriculture (FAO, 2008). Conservation agriculture has been reported in a growing amount of literature to increase ecosystem service delivery (Choudhary et al., 2018) while preventing organic matter loss and biodiversity in agricultural soils (Bender et al., 2016). Long-term pioneering studies in conservation agriculture have so far produced tangible evidence that this farming model enhances soil species biodiversity (Mutema et al., 2013; Sithole et al., 2017), therefore system stability and resilience.

Other authors have stressed the importance of organic agriculture for sustainable intensification by preserving farmland diversity and functionality. This model contributes to natural resource conservation by imitating natural environments through a richer diversity of crops and the absence of chemical intensification, thereby, improving soil quality, decomposition and water use efficiency (Thierfelder and Wall, 2009), for this reason, it has been supported by many authors as a prospective approach for alleviating biodiversity loss in agroecosystems (Batáry et al., 2011; McLaughlin and Mineau, 1995). Although organic agriculture is promoted as a sustainable substitute to conventional agriculture, some scientists in the crop sciences domains have however been very sceptical about the potential of organic agriculture in producing acceptable yields. And as a result, concerns of the capacity of organic agriculture to produce enough food for the growing global population have been raised and continue to be ardently debated in a growing frame of literature (Badgley and Perfecto, 2007; Cassman, 2007; Connor, 2013; Seufert et al., 2012). Therefore, to increase confidence about the stability of organic agriculture in terms of both sustainability and productivity, more comparative research is needed at different regional scales to compare the production potential of organic and conventional agriculture before and after adoption.

\subsection{Co-operation between agriculturalists and conservation ecologists}

Achieving sustainability in agriculture has proved to be challenging on its own, therefore, achieving both sustainability and biodiversity conservation in agriculture will be even more daunting. To tackle this, an integrated approach involving the broad diversification of information sources and the development of innovative data analysis techniques will be necessary at all levels (Doré et al., 2011). For the longest time, the 
sectors of agriculture and conservation ecology have functioned independently, with each having its principles and norms. Agricultural scientists and conservation ecologists are both custodians of natural resources and land; therefore, they hold the fundamental knowledge and skills necessary to manage and sustain biodiversity and their associated environment. Therefore, they must be allies in global efforts to achieve biodiversity conservation and sustainability in agriculture. To date research in conservation, has been the most effective scientific effort to accomplish biodiversity conservation (Brussaard et al., 2010), therefore, conservation scientists must broaden their stances and join forces with farmers, agricultural scientists and Agri-industry to support the integration and advancement of biodiversity conservation in agriculture. Together with policymakers who endorse policy advancement, the sectors of conservation and agriculture can work collectively to achieve their mutual goals of sustain the needs of the ever-increasing human population, while safeguarding the natural resources and ecological processes, which are fundamental for long-term human survival.

\subsection{Enhancing environmental literacy}

Environmental literacy increases knowledge about the responsiveness to changes or disturbance within the environment. Environmentally literate individuals have the necessary expertise and information to examine and correctly handle environmental matters (Wong et al., 2018). The general lack of environmental literacy is one of the most fundamental challenges and obstacle in achieving sustainability and natural resource conservation (Jordan et al. 2009; Mustafa et al. 2019). The fact that less than 20 percent of farmers and the public are considered environmentally knowledgeable cannot be ignored any longer (Sishuba, 2019). A study conducted by Rickinson (2001), identified significant correlations between higher levels of environmental literacy with a higher degree of pro-environment actions. Therefore, effective adoption and success of sustainable intensification will generally require a participatory approach which includes the training of farmers, and action research (Pretty et al., 2018) through workshops and consultations. Within this setting, stakeholders in environmental sciences can contribute to the improvement of environmental literacy of farmers by providing structured training programmes on managing their agroecosystems sustainably to conserve biodiversity.

\subsection{Advancement of policy planning and application}

Policymakers hold the key to influence and endorse changes in policy. Advances in policy can have significant influences on many environmental issues surrounding agriculture and conservation; therefore, as much as co-operation from agricultural and conservation scientists is needed, efforts from policymakers are also needed to effectively ensure sustainable food production and biodiversity conservation. It is greatly recognised that during policy planning, the issues of sustainable use and conservation of biodiversity are constantly side-lined unlike other policy challenges (Young et al., 2014). As a result, some views strongly suggest that biodiversity conservation research is constantly overlooked in decision-making (Garibaldi et al., 2019; Spierenburg, 2012), therefore policymakers owe it to science and society to widen their stances and change this narrative. Policy legislatures can significantly contribute to biodiversity conservation in agriculture by using knowledge generated from research and co-operation between 
agricultural and conservation scientists to, (1) develop practical approaches of incorporating biodiversity considerations within national agrarian policies and, (2) promote sustainable intensification by endorsing policy changes that reduce the subsidies that lead to unsustainable agriculture.

\section{Conclusion}

Humanity is depended on agriculture for food and sustenance; therefore, its sustainability is important for food security and economic growth. Biodiversity is fundamental for productivity and resilience. Therefore, to safeguard food production and sustainability, there is a need to support the advancement of biodiversity conservation in agricultural landscapes to improve functionality and productivity through ecosystem services the biodiversity provides. A few promising efforts aimed at promoting biodiversity conservation in agriculture have been made by the UN through its agricultural entity FAO. For instance, the sustainable development agenda for 2030 has placed biodiversity at the core of every sector related to sustainable agriculture and the economy. However, as much as this is encouraging, more efforts are still necessary, more especially from the sectors of agriculture and conservation; through engagements and research co-operation, these sectors can work together to better identify and facilitate effective methods for biodiversity conservation. While stakeholders are responsible for the planning and implementation of environmental approaches to mitigate threats, it is also the responsibility of the society to engage more in environmental education. This will ensure that natural resources are safeguarded because we owe it to our generation and the upcoming generations to conserve and take care of natural resources such as biodiversity so that they can take care of us.

\section{Acknowledgements}

The National Research Foundation of South Africa and the Department of Science and Technology supported this work through the NRF/DST innovationfunding instrument (Grant Number: 106082). The ARC-Small Grain provided support and facilities.

\section{References}

Adenle, A., Wedig, K., Azadi, H. (2019). Sustainable agriculture and food security in Africa: The role of innovative technologies and international organizations. Technology in Society 58,1-17.

Altieri, M. (2002). 'Agroecology: the science of natural resource management for poor farmers in marginal environments.' Agriculture, Ecosystems and Environment 93, 1-24.

Altieri, M., Nicholls, C., Fritz, M. (2016). Manage insects on your farm: A Guide to Ecological Strategies. Sustainable Agriculture Research and Education (SARE), College Park, MD.

Badgley, C., Perfecto, I. (2007). Can organic agriculture feed the world-science to the rescue? Renewable Agriculture and Food Systems 22, 80-82.

Balvanera, P., Pfisterer, A., Buchmann, N., He, J.-S., Nakashizuka, T., Raffaelli, D., Schmid. (2006). Quantifying the evidence for biodiversity effects on ecosystem functioning and services. Ecology Letters 9, 1146-1156.

Barrios, E. (2007). Soil biota, ecosystem services and land productivity. Ecology Economics 64, 269-285. 
Batáry, P., Baldi, A., Kleijn, D., Tscharntke, T. (2011). Landscape-moderated biodiversity effects of agrienvironmental management: a meta-analysis. Proceedings of the Royal Society B: Biological Sciences 278, 1894-1902.

Bender, S., Wagg, C., van der Heijden, M. (2016). An Underground Revolution: Biodiversity and Soil Ecological Engineering for Agricultural Sustainability. Trends in Ecology \& Evolution 31, 440452.

Brown, E., Williams, B. (2016). Ecological integrity assessment as a metric of biodiversity: are we measuring what we say we are? Biodiversity Conservation 25, 1011-1035.

Brussaard, L., Caron, P., Campbell, B., Lipper, L., Mainka, S., Rabbinge, R., Babin, D., Pulleman, M. (2010). Reconciling biodiversity conservation and food security: scientific challenges for a new agriculture. Current Opinion in Environmental Sustainability 2, 34-42.

Brussaard, L., Hauser, S., Tian, G. (1993). Soil fauna activity in relation to the sustainability of agricultural systems in the humid tropics, in: Mulongoy, K., Merckx, R. (Eds.), Soil Organic Matter Dynamics and Sustainability of Tropical Agriculture. Wiley, New York, pp. 455-460.

Cardinale, B. (2011). Biodiversity improves water quality through niche partitioning. Nature 472, 86-89.

Cassman, K. (2007). Editorial response by Kenneth Cassman: can organic agriculture feed the world-science to the rescue? Renewable Agriculture and Food Systems 22, 83-84.

Choudhary, M., Datta, A., Jat, H., Yadav, A., Gathala, M., Sapkota, T., Das, A., Sharma, P., Jat, M., Singh, R., Ladha, J. (2018). Changes in soil biology under conservation agriculture based sustainable intensification of cereal systems in Indo-Gangetic Plains. Geoder. 313, 193-204.

Connor, D. (2013). Organically grown crops do not a cropping system make and nor can organic agriculture nearly feed the world. Field Crops Research 144, 145-147.

Crotty, F., Fychan, R., Scullion, J., Sanderson, R., Marley, C. (2015). Assessing the impact of forage crops on soil biodiversity and abundance. Soil biology and biochemistry 91, 119-126.

De Schutter, O. (2010). Agroecology and the right to food, in: Proceedings of the Human Rights Council 16th Session Agenda Item 3. United Nations General Assembly, New York.

DEA. (2015). National Biodiversity Strategy and Action Plan (NBSAP). Department of Environmental affairs South Africa, Pretoria.

Diaz, S., Fargione, J., Chapin, F., Tilman, D. (2006). Biodiversity Loss Threatens Human Well-Being. PLoS Biology 4.

Doré, T., Malézieux, E., Munier-Jolain, N., Tchamitchian, M., Tittonell, P. (2011). Facing up to the paradigm of ecological intensification in agronomy: Revisiting methods, concepts and knowledge. European Journal of Agronomy 34, 197-210.

Dose, H., Fortuna, A., Cihacek, L., Norland, J., DeSutter, T., Clay, D., Bell, J. (2015). Biological indicators provide short term soil health assessment during sodic soil reclamation. Ecological Indicators 58, 244-253.

FAO. (2018). Transition towards sustainable food and agriculture. Food and Agriculture Organization of the United Nations, Rome, Italy.

FAO. (2015). Incentives for Ecosystem Services in Agriculture (IES). Food and Agriculture Organization of the United Nations, Rome, Italy.

FAO. (2009). Global Agriculture towards 2050. Food and Agriculture Organization of the United Nations.

FAO. (2008). Soil macrofauna field manual: Technical level. Food and Agricultural Organisation of The United Nations, Rome, Italy.

Garibaldi, L., Pérez-Méndez, N., Garratt, M., Gemmill-Herren, B., Miguez, F., Dicks, L. (2019). Policies for Ecological Intensification of Crop Production. Trends in Ecology and Evolution 34, 282-286.

Gliessman, S. (2015). Agroecology: The Ecology of Sustainable Food Systems, 3rd ed. CRC Press, Boca Raton, USA.

Gomiero, T., Pimentel, D., Paoletti, M. (2011). Environmental impact of different agricultural management practices: Conventional vs. organic agriculture. Critic Rev. Plant Scie. 30, 95-124.

Holt-Giménez, E., Altieri, M. (2013). Agroecology, food sovereignty, and the new Green Revolution. Agroecology and Sustainable Food Systems 37, 90-102.

IAASTD. (2009). International assessment of agricultural knowledge, science and technology for development: the synthesis report, in: McIntyre, B., Herren, H., Wakhungu, J., Watson, R. (Eds.), . Island Press, Washington, DC. 
IPES-Food. (2016). From Uniformity to Diversity: A Paradigm Shift from Industrial Agriculture to Diversified Agroecological Systems.

Isgren, E., Ness, B. (2017). Agroecology to Promote Just Sustainability Transitions: Analysis of a Civil Society Network in the Rwenzori Region, Western Uganda. Sustainability 9, 1-20.

Jing, X., Sanders, N., Shi, Y., Chu, H., Classen, A., Zhao, K., Chen, L., Shi, Y., Jiang, Y., He, J. (2015). The links between ecosystem multifunctionality and above- and belowground biodiversity are mediated by climate. Nat. Commun. 6, 8159-9159.

Jordan, R., Singer, F., Vaughan, J., Berkowitz, A. (2009). What should every citizen know about ecology? Frontiers in Ecology and Environment 7, 495-500.

Khumalo, S., Chirwa, P., Moyo, B., Syampungani, S. (2012). The status of agrobiodiversity management and conservation in major agroecosystems of Southern Africa. Agriculture, Ecosystems and Environment 157, 17-23.

McLaughlin, A., Mineau, P. (1995). The impact of agricultural practices on biodiversity. Agriculture, Ecosystems \& Environment 55, 201-212.

Millennium Ecosystem Assessment. (2005). Ecosystems and Human Well-being: Biodiversity Synthesis. World Resources Institute, Washington, DC.

Moore, E. (2015). Drought management factsheet (No. 8), Tillage, residue management and their effects on soil moisture. Agriculture and Agri-Food Canada, Canada.

Mustafa, G., Latif, I., Bashir, M., Shamsudin, M., Noordin, W., Daud, W. (2019). Determinants of farmers' awareness of climate change. Applied Environmental Education \& Communication 18, 219-233.

Mutema, M., Mafongoya, P., Nyagumbo, I., Chikukura, L. (2013). Effect of crop residue and reduced tillage on macrofauna abundance. JOS 8, 5-16.

Palomo-Campesino, S., González, J., García-Llorente, M. (2018). Exploring the Connections between Agroecological Practices and Ecosystem Services: A Systematic Literature Review. Sustainability $10,1-21$.

Petchey, O. (2007). Effects of environmental variability on ecological communities: testing the insurance hypothesis of biodiversity in aquatic microcosms, in: Vasseur, D., McCann, K. (Eds.), The Impact of Environmental Variability on Ecological Systems, The Peter Yodzis Fundamental Ecology Series. Springer, Dordrecht.

Pretty, J. (2008). Agricultural Sustainability: Concepts, principles and evidence, Philosophical: Transactions of The Royal Society. Biological Sciences 363, 447-465.

Pretty, J., Benton, T., Bharucha, Z., Dicks, L., Flora, C., Godfray, H., Goulson, D., Hartley, S., Lampkin, N., Morris, C., Pierzynski, G., Prasad, P., Reganold, J., Rockström, J., Smith, P., Thorne, P., Wratten, S. (2018). Global assessment of agricultural system redesign for sustainable intensification. Nature Sustainability $1,441-446$.

Rickinson, M. (2001). Learners and learning in environmental education: a critical review of the evidence. Environmental Education Research 7, 207-320.

Römbke, J., Schmelz, R., Kneebar, S. (2009). Field studies for the assessment of pesticides with soil mesofauna, in particular enchytraeids, mites and nematodes: design and first results. Soil Organisms 81, 237-264.

Seufert, V., Ramankutty, N., Foley, J. (2012). Comparing yields of organic and conventional agriculture. Nature 485, 229-232.

Sileshi, G., Akinnifesi, F., Ajayi, O., Chakeredza, S., Mng’omba, S., Nyoka, B. (2008). Towards sustainable management of soil biodiversity in agricultural landscapes in Africa. Biodiversity 9, 64-67.

Sishuba, S. (2019). Environmental literacy key to securing a sustainable future. Farmer's Weekly.

Sithole, N., Magwaza, L., Mafongoya, P. (2016). Conservation agriculture and its impact on soil quality and maize yield: A South African perspective. Soil. Till Rese. 162, 55-67.

Sithole, N., Magwaza, L., Mafongoya, P., Thibaud, G. (2017). Long-term impact of no-till conservation agriculture on abundance and order diversity of soil macrofauna in continuous maize monocropping system. Acta Agriculturae Scandinavica, Section B - Soil and Plant Science 1-10.

Spierenburg, M. (2012). Getting the message across: Biodiversity science and policy interfaces-A review. Gaia 21, 125-134.

Thierfelder, C., Wall, P. (2009). Effects of conservation agriculture techniques on infiltration and soil water content in Zambia and Zimbabwe. Soil and Tillage Research 105, 217-227. 
Tilman, D., Isbel, F., Cowles, J. (2014). Biodiversity and ecosystem functioning. Annual Reviews of Ecology and Evolution Systematic 45, 471-493.

Tscharntke, T., Clough, Y., Wanger, T., Jackson, L., Motzke, I., Perfecto, I., Vandermeer, J., Whitbread, A. (2012). Global food security, biodiversity conservation and the future of agricultural intensification. Biology Conservation 151, 53-59.

Twardowski, J. (2010). The effect of reduced tillage systems in winter wheat crop on the assemblages of epigeal and soil arthropods. Publisher of Wrocław University of Environmental and Life Sciences, Wrocław.

Van Hook, T. (1994). The Conservation Challenge in Agriculture and the Role of Entomologists. Florida Entomologist 77, 42-73.

Wilson, E. (1992). The diversity of life. The Belknap Press of Harvard University Press, Cambridge, Massachusetts.

Wong, C., Afandi, S., Ramachandran, S., Kunasekaran, P., Chan, J. (2018). Conceptualizing environmental literacy and Factors affecting pro-environmental Behaviour. International Journal of Business and Society $19,128-139$.

Young, J., Waylen, K., Sarkki, S., Albon, S., Bainbridge, S., Balian, E., Davidson, J., Edwards, D., Fairley, R., Margerison, C., McCracken, D., Owen, R., Quine, C., Stewart-Roper, C., Thompson, D., Rob Tinch, R., Hove, S., Watt, A. (2014). Improving the science-policy dialogue to meet the challenges of biodiversity conservation: having conversations rather than talking at one-another. Biodiversity Conservation 23, 387-404. 